Апnи Rev Med. 2009 ; 60: 321-337. doi:10.1146/annurev.med.60.101707.125712.

\title{
Polycystic Kidney Disease
}

\author{
Peter C. Harris and Vicente E. Torres \\ Division of Nephrology and Hypertension, Mayo Clinic, Rochester, Minnesota 55905
}

\begin{abstract}
A number of inherited disorders result in renal cyst development. The most common form, autosomal dominant polycystic kidney disease (ADPKD), is a disorder most often diagnosed in adults and caused by mutation in $P K D 1$ or $P K D 2$. The PKD1 protein, polycystin-1, is a large receptor-like protein, whereas polycystin- 2 is a transient receptor potential channel. The polycystin complex localizes to primary cilia and may act as a mechanosensor essential for maintaining the differentiated state of epithelia lining tubules in the kidney and biliary tract. Elucidation of defective cellular processes has highlighted potential therapies, some of which are now being tested in clinical trials. ARPKD is the neonatal form of PKD and is associated with enlarged kidneys and biliary dysgenesis. The disease phenotype is highly variable, ranging from neonatal death to later presentation with minimal kidney disease. ARPKD is caused by mutation in PKHDl, and two truncating mutations are associated with neonatal lethality. The ARPKD protein, fibrocystin, is localized to cilia/basal body and complexes with polycystin-2. Rare, syndromic forms of PKD also include defects of the eye, central nervous system, digits, and/or neural tube and highlight the role of cilia and pathways such as Wnt and Hh in their pathogenesis.
\end{abstract}

\section{Keywords}

ADPKD; ARPKD; polycystin-1; polycystin-2; fibrocystin

\section{INTRODUCTION}

Polycystic kidney disease (PKD) is a group of monogenic disorders that result in renal cyst development. The morbidity associated with the most common forms, autosomal dominant PKD (ADPKD) and autosomal recessive PKD (ARPKD), is largely limited to the kidney and liver (and, in ADPKD, vasculature) and extends from neonates to old age. In a rarer group of mainly recessively inherited pleiotropic disorders, cystic kidneys or cystic dysplasia are part of a set of developmental phenotypes. Over the past 15 years, positional cloning approaches have identified more than 20 genes causing these disorders. The common forms of PKD are associated with a low level of genic heterogeneity but extreme allelic heterogeneity, whereas marked genic heterogeneity is found in syndromic forms of PKD. Novel protein families have been identified, the functions of which are only now coming to light. A factor that unites all these disorders is the involvement of the primary cilium and the base of the cilium, the basal body, in their pathogenesis. PKD proteins, and orthologs in other species, have been localized to cilia/basal body, and loss or abnormalities of cilia in the kidney are associated with cyst

Copyright $\odot 2009$ by Annual Reviews. All rights reserved

harris.peter@mayo.edu

DISCLOSURE STATEMENT

Dr. Torres receives research funding from Otsuka Pharmaceuticals for clinical trials. 
development. Rapid progress toward understanding the etiology and pathogenesis of these diseases is revealing possible therapeutic targets that are now being assessed.

\section{AUTOSOMAL DOMINANT POLYCYSTIC KIDNEY DISEASE Clinical Description}

ADPKD is typically diagnosed in adults and, with an incidence of 1:400-1000, is one of the most common monogenic disorders. The disease is characterized by the progressive, bilateral development and enlargement of focal cysts that in many cases ultimately result in end-stage renal disease (ESRD) (1). In the United States, $4.4 \%$ of patients requiring renal replacement therapy (dialysis or transplant) have ADPKD. There is considerable phenotypic variability, however, from rare infantile cases with large cystic kidneys to patients in their tenth decade with adequate renal function (2). ADPKD is a systemic disease, with cyst development also occurring in the liver, pancreas, seminal vesicles, and arachnoid. In the liver, it can (rarely; more often in women) result in severe polycystic liver disease (PLD) requiring surgical intervention. Other notable phenotypes in ADPKD involve the vasculature, with intracranial aneurysms approximately five times more common than in the general population and significant morbidity/mortality associated with aneurysmal rupture (1). Typical presenting symptoms include flank pain, hematuria, renal colic, urinary tract infections, and hypertension (3). ADPKD can generally be diagnosed in at-risk adults by imaging of the kidney by ultrasound, CT, or MRI with multiple cysts generally visible that increase in size and number with age. Recent MRI data from an observational trial of ADPKD showed that kidneys increase on average $5.27 \%$ per year, but with a wide range of variability, and that renal volume can be used to monitor disease progression before a measurable decline in function (4).

\section{Genetics}

ADPKD is genetically heterogeneous with two genes identified, PKD1 (16p13.3) and PKD2 (4q21), plus a few unlinked families described (5-8). PKD1 accounts for $~ 85 \%$ of cases in clinically identified populations (9) and is a significantly more severe disease; the average age at onset of ESRD is 20 years younger in PKD1 than in PKD2 [54.3 years versus 74.0 years (10)]. The greater severity of PKD1 appears to be due to the development of more cysts at an early age, not to faster growth (11). Both PKD1 and PKD2 can be associated with severe PLD and vascular abnormalities. A separate, genetically heterogeneous disease, autosomal dominant polycystic liver disease (ADPLD), causes severe PLD but with no or minimal renal cysts $(12,13)$.

The PKDl gene (46 exons; genomic extent, $50 \mathrm{~kb}$ ) encodes a large transcript with an open reading frame (ORF) of 12,909 bp $(6,7)$. The $5^{\prime} 33$ exons of $P K D 1$ lie in a region that is duplicated six times elsewhere on chromosome 16, complicating molecular diagnostics. PKD2 (15 exons; $68 \mathrm{~kb}$ ) has an ORF of $2904 \mathrm{bp}(8)$. Screening of ADPKD patients indicates that a wide range of mutations cause this disease; 314 different truncating mutations (in 400 families) to $P K D 1$ and 91 truncating mutations (in 166 families) to $P K D 2$ have been described. An additional one quarter of mutations are missense. Likely mutations are detected in $~ 90 \%$ of patients, making molecular diagnostics an option when diagnostics by renal imaging is equivocal (9). This is particularly helpful for obtaining a definite diagnosis in a young person who is a potential living related donor. The type of mutation (truncating or missense) does not seem to be strongly associated with the phenotype $(14,15)$, but mutation position in $P K D l$ has been weakly associated with severity of renal disease and to the development of intracranial aneurysms $(14,16)$. The majority of patients have an affected parent, but $>10 \%$ of families can be traced to a new mutation; two cases of mosaicism have recently been described $(17,18)$. 


\section{Lessons from Animal Models}

Mice homozygous for $P k d l$ or $P k d 2$ mutations typically die at E12.5-16.5 with grossly cystic kidneys and pancreas, indicating that loss of all gene product results in cyst development (19). Heterozygous animals develop only a few cysts, mainly in the liver, at older ages (20). Recent studies of conditional knockouts of $P k d l$ show that inactivation before postnatal day 13 results in rapidly progressive cystic disease whereas later inactivation results in a much milder course, indicating a developmental switch that may be associated with normal downregulation of the protein at that time $(21,22)$. The focal cyst development seen in human ADPKD may be due to somatic second hits; screening of $P K D 1$ and $P K D 2$ in cyst lining cells has identified loss of heterozygosity and other somatic mutations $(23,24)$. A PKD2 model (WS25) with a hypermutable allele also develops progressive cystic disease in combination with a null allele $\left(P K D 2^{W S 25 /-}\right)(25)$. However, dosage reduction of the protein in two $P k d 1$ animal models with hypomorphic alleles that generate $<20 \%$ of the normally spliced product indicates that cysts can develop even if the protein is not completely lost (26).

\section{Roles of the ADPKD Proteins}

The PKD1 protein, polycystin-1, is a large (4303 amino acids) integral membrane protein with 11 transmembrane domains and an extracellular region consisting of a variety of domains, including 12 PKD domains (an immunoglobulin-like fold), which in other proteins are associated with protein-protein and protein-carbohydrate interactions $(6,27,28)$ (Figure 1). Overall, polycystin- 1 has the structure of a receptor or adhesion molecule. Polycystin-2 (the PKD2 protein) is a nonselective cation channel that transports calcium $(29,30)$. The polycystins form a distinct sub-family (TRPP) of transient receptor potential (TRP) channels. Polycystin-2 shows homology with the final six-transmembrane region of polycystin-1. Polycystin-1 is cleaved at the G protein-coupled receptor proteolytic site (GPS) domain, which may be important to activate the protein (31). Interestingly, mice with a mutation that disrupts cleavage are viable (to P28) with enlarged, cystic kidneys, suggesting a role for the uncleaved product during development (32). Cleavage of the C-terminal tail and migration to the nucleus (similar to notch signaling) has also been suggested in two studies $(33,34)$. Polycystin- 2 may also regulate proliferation and differentiation by controlling progression through the cell cycle (35).

There is good evidence that the polycystins form a complex, and a major role of this complex may be to regulate levels of intracellular $\mathrm{Ca}^{2+}$. The polycystins have been localized to various sites. These include involvement in cell-cell and cell-matrix interactions, as well as in the endoplasmic reticulum in the case of polycystin-2, but the most compelling evidence associating them with PKD supports a location on primary cilia $(36,37)$. Most cells have a single primary cilium. In the case of tubular epithelial cells, this extends into the lumen of the tubule. This cilium has a 9+0 microtubule arrangement (nonmotile) and+has a sensory function. The base of the cilium, the basal body, is derived from the mother centriole; the external part of the cilium consists of a microtubule core (the axoneme) covered by a ciliary membrane. Evidence that cilia are important in PKD comes from animal models in which intraflagellar transport (IFT), which is required for movement of proteins in the cilium and hence ciliary formation, was disrupted by kidney-specific inactivation of the anterograde IFT motor component KIF3A (38). These animals develop renal cysts. Data indicate that the polycystin complex acts as a flow sensor on the cilium (39). Mechanical or flow-induced bending of cilia is associated with a $\mathrm{Ca}^{2+}$ influx into the cell, which occurs through the polycystin- 2 channel (40). This mechanosensory response is lost in polycystin-1-deficient cells (39). Urinary vesicles that contain polycystin-1 may help mediate this flow response $(41,42)$, similar to the role that nodal vesicular parcels play in transmitting signals in the node (43). The node is a ciliated structure formed during development that is involved in establishing left-right body asymmetry. Asymmetric calcium signaling through the polycystin-2 channel appears to be 
important in this process, which is consistent with laterality defects found in $P k d 2^{-/-}$mice $(44,45)$.

A family of polycystin-like proteins have now been identified, four with structures similar to polycystin-1 and three like polycystin-2 (46), although no others seem to be linked to PKD. PKDREJ (PKD receptor for egg jelly) is only expressed in the male germline, and $\mathrm{Pkdrej}^{-/-}$ mice are fertile but with reduced reproductive success. PKDREJ appears to have a role in the zona pellucida-evoked acrosome reaction (47). The polycystins PKD2L1 and PKD1L3 are expressed in taste cells and form a complex that is the sour taste receptor (48). These proteins are also important for $\mathrm{pH}$ sensing in cerebrospinal fluid (49).

Consistent with the polycystin complex having a role in $\mathrm{Ca}^{2+}$ regulation, PKD cells display alterations in intracellular $\mathrm{Ca}^{2+}$ homeostasis and possibly have a reduced level of intracellular $\mathrm{Ca}^{2+}(50)$. In addition, increased levels of cAMP have been found in several PKD animal models and this may be directly related to the reduced $\mathrm{Ca}^{2+}$ (Figure 2) (51-53). In PKD cells, cAMP stimulates MAPK/ERK signaling, which depends on Src, Ras and B-Raf, compared to an inhibitory response in normal cells $(54,55)$. This altered response can be reversed by treatment with a $\mathrm{Ca}^{2+}$ channel activator or a $\mathrm{Ca}^{2+}$ ionophore to increase intracellular $\mathrm{Ca}^{2+}$ levels in PKD cells (56). As well as activating the MAPK/ERK pathway and cell proliferation in PKD cells, cAMP also stimulates chloride-driven fluid secretion.

Patients with contiguous deletions of $P K D 1$ and the adjacent tuberous sclerosis gene (TSC2) have unusually severe PKD, suggesting synergy between these intersecting pathways (Figure 2) (57). Activation of $\mathrm{mTOR}$ in PKD and possible interaction of the TSC2 protein (tuberin) and polycystin-1 also show crosstalk between these pathways (58).

\section{Potential Therapies and Clinical Trials}

Until now, therapy for ADPKD has been directed toward limiting its complications. Cardiovascular complications, to a large extent related to hypertension, are a major cause of morbidity and the leading cause of mortality. Despite this, optimal antihypertensive regimens and blood pressure targets remain uncertain. HALT-PKD is a clinical trial designed to determine whether combined therapy with an angiotensin I-converting enzyme inhibitor (ACEI) and an angiotensin II-receptor blocker (ARB) is superior to an ACEI alone in delaying the progression of cystic kidney disease (CKD) in patients with CKD stage 1 or 2 or in slowing down the decline of renal function in patients with CKD stage 3. HALT-PKD will also determine whether a low blood pressure target $(<110 / 75)$ is superior to a standard blood pressure target (120-130/70-80) in the group of patients with preserved function. A smaller clinical trial seeks to determine whether treatment of pediatric or young adult ADPKD patients with a statin can slow down the progression of kidney and heart disease (Table 1).

Better understanding of signaling pathways and cellular changes associated with ADPKD has suggested possible therapies to directly inhibit the development or growth of cysts, some of which are now being tested in clinical trials (Table 1). It is known that vasopressin, via V2 receptors (VPV2R), has a role in regulating cAMP levels in the distal nephron and collecting duct, a major site of ADPKD cysts. This suggested that VPV2R antagonists may be beneficial. Animal studies, including in a $P k d 2$ model, showed a dramatic reduction in cyst development $(51,52)$. Phase II clinical trials of tolvaptan, a VPV2R inhibitor, have now been completed and a phase III double-blind placebo-controlled trial has begun. Another means to regulate cellular cAMP levels is through somatostatin's action on SST2 receptors that are present in the liver and kidney. A stable somatostatin analogue, octreotide, has proved effective at limiting progression in liver and kidney cystic disease in a rat model of PKD (59). Preliminary studies in human ADPKD indicate that octreotide may inhibit cyst growth, and further clinical trials of long-acting somatostatin analogs are under way (Table 1) (60). The suggested activation of 
the mTOR pathway in PKD has prompted testing of mTOR inhibitors. Administration in three rodent models has resulted in a reduction in cyst growth and preservation of renal function (58). In addition, analysis of transplanted ADPKD patients who received mTOR inhibitors as the immunosuppressive agent showed a reduction in size of the native kidney and the liver compared to other immunosuppressive regimens, thus justifying further clinical trials (58, $61)$.

A number of other compounds have shown efficacy in animal models of PKD but have not yet been tested in clinical trials (Figure 2). Administration of small-molecule CFTR inhibitors of the thiazolidinone and glycine hydrazide classes in a $P k d l^{f l o x /}{ }^{-} ; \mathrm{Ksp}-\mathrm{Cre}$ mouse model of rapidly progressive ADPKD slowed cyst expansion and protected renal function (62). Chloride-driven fluid secretion into cysts requires the coordinated activity of apical CFTR and basolateral $\mathrm{Na} / \mathrm{K} / 2 \mathrm{Cl}$ cotransporter NKCC1, plus basolateral recycling of $\mathrm{Na}^{+}$and $\mathrm{K}^{+}$and maintenance of a hyperpolarized membrane potential by the basolateral $\mathrm{Na}^{+}, \mathrm{K}^{+}$-ATPase and by $\mathrm{K}^{+}$channels such as the $\mathrm{Ca}^{2+}$-dependent $\mathrm{K}^{+}$channel KCa3.1. Direct inhibitors of $\mathrm{KCa} 3.1$ that are well tolerated in vivo and are in phase III clinical trials for sickle cell disease inhibited cystogenesis in vitro $(63,64)$. Triptolide, a product from a traditional Chinese herb that induces $\mathrm{Ca}^{2+}$ release in a polycystin-dependent manner, inhibited cyst development and protected renal

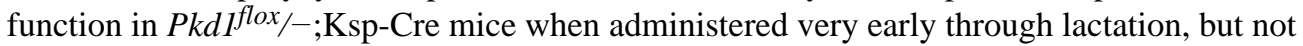
when the treatment was started later at P4 $(65,66)$. ErbB tyrosine kinase and c-Src inhibitors inhibited both renal and hepatic cyst development and protected renal function in various rodent models of polycystic kidney disease, while MAPK/ERK kinase (MEK) and cyclin-dependent kinase inhibitors inhibited the development of PKD in the $p c y$ model and in the $j c k$ and $c p k$ models, respectively $(67-69,74)$.

In addition, some compounds have shown efficacy in animal models of PKD by mechanisms not illustrated in Figure 2. Ribozymes targeting either vascular endothelial growth factor (VEGF) receptor 1 (VEGFR1) or 2 (VEGFR2) mRNA slowed the progression of cystic disease in Han:SPRD Cy/ rats (70). A tumor necrosis factor-alpha (TNF- $\alpha$ ) inhibitor prevented cyst development in $P k d 2^{+/-}$animals, presumably because TNF- $\alpha$ in cystic tissues and cyst fluids disrupts the localization of PC2 to the plasma membrane and primary cilia (71). An inhibitor of 20-hydroxyeicosatetraenoic acid (20-HETE), an endogenous cytochrome P450 metabolite of arachidonic acid with mitogenic properties, reduced kidney size and improved survival in $b p k$ mice (72). Diets enriched in long-chain $n$-3 polyunsaturated fatty acids have been shown to exert anti-inflammatory effects and to slow renal cystic enlargement and functional deterioration in animal models of PKD. However, a small prospective clinical trial of eicosapentaenoic acid (EPA) failed to demonstrate a beneficial effect in ADPKD patients with a mean total kidney volume of $1563 \mathrm{ml}$ and a mean serum creatinine of $1.56 \mathrm{mg} / \mathrm{dl}$ (73).

\section{AUTOSOMAL RECESSIVE POLYCYSTIC KIDNEY DISEASE}

\section{Clinical Description}

ARPKD has been estimated to have an incidence of 1:20,000 and typically presents in utero or during the neonatal period with greatly enlarged, echogenic kidneys. The most extreme cases are associated with the Potter's phenotype, consisting of pulmonary hypoplasia, characteristic facies and spine and limb abnormalities. A significant proportion of cases (up to 30\%) die by the neonatal period, primarily of respiratory insufficiency. In the survivors, hypertension and renal insufficiency, including ESRD (up to a third of children require renal replacement therapy), are the major signs of renal disease (75). The other pathognomonic sign of disease is biliary dysgenesis resulting in congenital hepatic fibrosis, plus intrahepatic bile duct dilatation (Caroli disease). The disease presentation is not limited to the neonatal period; it can be diagnosed in childhood, or even adolescence or adulthood (76). These later-presenting cases typically have less severe kidney disease, and complications of the liver disease are more 
common. These complications include those associated with portal hypertension, such as bleeding esophageal or gastric varices, and cholangitis related to Caroli disease.

\section{Genetics}

ARPKD is caused by mutation in one gene, PKHDl (6q21). PKHD1 (polycystic kidney and hepatic disease 1) has 67 exons and covers a genomic region of $470 \mathrm{~kb}$. The longest ORF has $12,222 \mathrm{bp}$, but there may be other alternatively spliced products $(77,78)$. PKHDI exhibits a high level of allelic heterogeneity, with 303 different mutations described on $>650$ alleles. Approximately $40 \%$ of mutations are predicted to be truncating and $60 \%$ missense. About one third of mutations are unique to a single family, and a small number are enriched in specific geographic areas. One missense change, T36M, is relatively frequent (17\% of mutant alleles) and is of European origin. A clear genotype/phenotype correlation has been described in ARPKD, with two truncating mutations always associated with the most severe phenotype, neonatal death (79). This indicates that many missense changes are not fully penetrant alleles; they are associated with production of some functional protein. Molecular diagnostics in ARPKD is helpful to make a firm diagnosis, especially in cases with less severe disease, and to facilitate preimplementation genetic diagnostics and prenatal diagnostics.

\section{Lessons from Animal Models}

Six different knockout mouse models of ARPKD have been described with a variety of different $P k h d l$ mutations, plus a spontaneous rat model, PCK $(78,80,81)$. All of the mouse models develop biliary dysgenesis and fibrosis, similar to human ARPKD, but kidney disease is generally mild and late-onset compared to severe human ARPKD. Pancreatic cysts, including grossly enlarged pancreatic cystic disease, is common. The PCK rat has progressive cystic disease in the liver and kidney and has been a favored model to test potential therapies (51). Shortened and abnormal ciliary structures, described in several rodent models, are associated with reduced $P k h d l$ expression in cells (81-83). This is in contrast to ADPKD, where cilia are thought to be normal. Whereas most PKD genes are widely expressed, PKHDI has more limited expression in kidney, liver, pancreas, and lung, perhaps explaining the limited range of phenotypes compared to syndromic forms of PKD that are associated with ciliary defects (78).

\section{Roles of the ARPKD Protein}

The PKHDl protein, fibrocystin (also called polyductin), has 4074 amino acids and is attached to the membrane via a single transmembrane domain (Figure 1) (78). The large extracellular region contains 12 TIG/IPT domains (immunoglobulin-like fold shared by plexins and transcription factors). Fibrocystin has been found in the same complex as polycystin-2 and has been localized to primary cilia, as well as to the basal body (83-87). Fibrocystin is thought to be cleaved at a proprotein convertase site in the extracellular region $(42,88)$. In addition, similar to polycystin-1, cleavage and transport of the $\mathrm{C}$-tail to the nucleus has been described ( 88 , 89). The precise function of fibrocystin is at present unknown, but it may mediate its activity through polycystin-2. One fibrocystin homolog, fibrocystin-L, has been described in mammals; it has a similar overall structure but does not seem to be associated with PKD (90).

\section{PLEIOTROPIC FORMS OF POLYCYSTIC KIDNEY DISEASE}

\section{Genetic and Phenotypic Heterogeneity}

A number of rare syndromic disorders have renal cysts or cystic dysplasia as part of their phenotype (91). These disorders have provided important insights into mechanisms that may be associated with cystogenesis and, in particular, the role of cilia and/or the basal body in that process. Most of the implicated proteins have been localized to the centrosomal/basal body 
and/or the cilium, and in many disorders, ciliary defects have been described (91). These ciliopathies have considerable phenotypic overlap, and recently it has become clear that often the same gene is associated with more than one disease. The syndromic PKD disorders include nephronophthisis (NPHP), which in turn includes Senior-Loken syndrome (SLS) (92); Joubert syndrome and related disorders ( JSRD) (93); Meckel syndrome (MKS); Bardet-Biedel syndrome (BBS) (94); and orofacial digital syndrome (OFDS) (95). These diseases and the genes involved are summarized in Figure 3.

As well as renal cystic disease/cystic dysplasia, a number of other phenotypes are found in two or more of the diseases. These include biliary dysgenesis/hepatic fibrosis; eye defects; central nervous system/neural tube abnormalities; distal limb/digit anomalies; and developmental delay/mental retardation. A high level of genetic heterogeneity is also evident: BBS has been linked to 14 different genes, MKS to nine, JSRD to five, and NPHP to nine. Many genes are implicated in multiple disorders, which both reveals the deficiencies of a phenotype-based classification system and illustrates the clinical variability associated with mutation at the same locus (93). Some of this variability may be related to allelic effects; the most severe phenotype (lethal MKS) is associated with two inactivating mutations in MKS3 or RPGRIPIL, whereas cases with at least one missense change or other hypomorphic allele at these loci are more often associated with JSRD. However, such a clear relationship is not evident with CEP290, and genetic background factors are likely to be most important. Indeed, in BBS and NPHP, oligogenic inheritance has been demonstrated: mutation at more than one locus is required for disease development $(94,96,97)$. Similarly, hypomorphic $M K S 1$ alleles have been found to modify the phenotype in BBS (98).

\section{Syndromic Forms of PKD are Ciliopathies}

The pleiotropic phenotypes in these syndromic disorders can likely be linked to defects in ciliary function and provide an insight into the signaling pathways that require functional cilia to operate. These disorders also shed light on other possible mechanisms by which ciliary abnormalities may be linked to cyst development.

Vision defects due to retinal degeneration are a feature of BBS, JSRD, and SLS that is found in $\sim 20 \%$ of patients with NPHP. In the rods and cones of the eye, a connecting cilium transports components to the outer segment, which contains discs of the light-absorbing pigment. Retinal degeneration has been demonstrated in several forms of BBS, and the implicated proteins are thought to be involved in ciliary formation and function, including involvement with IFT (94). A protein recently associated with JSRD and MKS, RPGRIPL1, is a homolog of the retinitis pigmentosa GTPase regulator-interacting protein (RPGRIP1) that causes Leber congenital amaurosis and has been localized to the connecting cilium of photoreceptors (99). Other sensory defects, such as loss of smell in BBS, are also likely due to defects in sensory cilia.

A number of developmental defects are associated with these ciliopathies, including polydactyly and other limb abnormalities (MKS, OFDS, BBS), defects of the neural tube (exencephaly), and other defects of the central nervous system (MKS, JSRD). Defects in Hedgehog (Hh) signaling have been associated with polydactyly and craniofacial abnormalities, and two murine IFT mutants were found to have similar defects (100). GLI1-3, the transcription factors activated by Hh signaling, have been localized to the distal tip of cilia, where cleavage of GLI3 into the repressed form, GLI3R, occurs (101). This processing is suppressed when Hh binds patched-1, releasing active GLI3A to be transported to the nucleus to activate target genes. Hence, functioning IFT (cilia) is required for activation of the Hh pathway. Recently, GLIS2 mutations have been associated with NPHP in one family (102). 
Certain phenotypes found in mouse models of BBS, particularly neural tube defects and disrupted stereociliary bundles in the cochlea, resemble phenotypes associated with disruption of the planar cell polarity (PCP) pathway, also known as the noncanonical Wnt pathway (103). PCP was discovered in Drosophila as a process determining organization, such as wing hairs and sensory bristles, that requires coordinated organization (polarity) of cells within the phase of a single cellular layer. In vertebrates, PCP controls developmental processes such as convergent extension and mitotic spindle orientation. A protein defective in NPHP2, inversin, has been suggested to be a switch between the $\beta$-catenin-dependent canonical Wnt pathway and the noncanonical PCP pathway, a change that may be dependent on fluid flow (104). Inversin also appears to be required for convergent extension during Xenopus gastrulation. Orientation of the mitotic spindle during division is thought to be important for the development of tubules so that epithelial cells divide along the longitudinal axis of the tubule. Defects in the orientation of the spindle have been detected in PKD animal models, including the PCK rat. This finding suggests that disoriented cell division may result in tubule enlargement in the transverse phase, similar to the fusiform dilation characteristic of some forms of PKD, such ase ARPKD (105).

\section{SUMMARY}

Gene identification in PKD has revealed a wide range of proteins associated with cyst development and has led to the discovery of two new protein families, the polycystins and the fibrocystins. An unanticipated connection has been found between PKD and the primary cilium. Polycystin-1 and -2 may act as a sensor on the cilium, essential for maintaining the differentiated state of the epithelia lining tubules in the kidney and biliary tract. Functioning cilia also seem important in other forms of PKD, and the diverse phenotypes associated with syndromic forms of PKD are likely explained by a lack of fully functional cilia and possible disruption of the Hh and Wnt pathways. Better understanding of the downstream consequences of PKD mutations has identified a number of therapeutic targets that are now being tested in preclinical and clinical trials.

\section{Glossary}

ADPKD

ARPKD

Pleiotropic

Genic heterogeneity

Allelic heterogeneity

ESRD

PKD1

PKD2

Pathognomonic

Syndromic PKD autosomal dominant polycystic kidney disease

autosomal recessive polycystic kidney disease

defect in a single gene is associated with a range of different phenotypes

more than one gene causes a disease with a similar phenotype

different mutations at the same locus are associated with the disease end-stage renal disease

form of autosomal dominant polycystic kidney disease that is caused by mutation in $P K D 1$, which encodes polycystin-1

form of autosomal dominant polycystic kidney disease that is caused by mutation in $P K D 2$, which encodes polycystin-2

phenotypically characteristic of a specific disease

pleiotropic disease in which polycystic kidney disease is just one of the phenotypic features 


\section{LITERATURE CITED}

1. Torres VE, Harris PC, Pirson Y. Autosomal dominant polycystic kidney disease. Lancet 2007;369:1287-301. [PubMed: 17434405]

2. Rossetti S, Harris PC. Genotype-phenotype correlations in autosomal dominant and autosomal recessive polycystic kidney disease. J. Am. Soc. Nephrol 2007;18:1374-80. [PubMed: 17429049]

3. Harris, PC.; Torres, VE. GeneReviews; Genetic Diseases Online Reviews at Gene-Test-GeneClinics. Seattle; Univ. Washington: 2006. Autosomal dominant polycystic kidney disease. http://www.ncbi.nlm.nih.gov/bookshelf/br.fcgi?book=gene\&part=pkd-ad

4. Grantham JJ, Torres VE, Chapman AB, et al. Volume progression in polycystic kidney disease. N. Engl. J. Med 2006;354:2122-30. [PubMed: 16707749]

5. European Polycystic Kidney Disease Consortium. The polycystic kidney disease 1 gene encodes a 14 $\mathrm{kb}$ transcript and lies within a duplicated region on chromosome 16. Cell 1994;77:881-94. [PubMed: 8004675]

6. Hughes J, Ward CJ, Peral B, et al. The polycystic kidney disease 1 (PKD1) gene encodes a novel protein with multiple cell recognition domains. Nat. Genet 1995;10:151-60. [PubMed: 7663510]

7. International Polycystic Kidney Disease Consortium. Polycystic kidney disease: the complete structure of the PKD1 gene and its protein. Cell 1995;81:289-98. [PubMed: 7736581]

8. Mochizuki T, Wu G, Hayashi T, et al. PKD2, a gene for polycystic kidney disease that encodes an integral membrane protein. Science 1996;272:1339-42. [PubMed: 8650545]

9. Rossetti S, Consugar MB, Chapman AB, et al. Comprehensive molecular diagnostics in autosomal dominant polycystic kidney disease. J. Am. Soc. Nephrol 2007;18:2143-60. [PubMed: 17582161]

10. Hateboer N, van Dijk MA, Bogdanova N, et al. Comparison of phenotypes of polycystic kidney disease types 1 and 2. Lancet 1999;353:103-7. [PubMed: 10023895]

11. Harris PC, Bae K, Rossetti S, et al. Cyst number but not the rate of cystic growth is associated with the mutated gene in ADPKD. J. Am. Soc. Nephrol 2006;17:3013-19. [PubMed: 17035604]

12. Davila S, Furu L, Gharavi AG, et al. Mutations in SEC63 cause autosomal dominant polycystic liver disease. Nat. Genet 2004;36:575-77. [PubMed: 15133510]

13. Drenth JP, Te Morsche RH, Smink R, et al. Germline mutations in PRKCSH are associated with autosomal dominant polycystic liver disease. Nat. Genet 2003;33:345-47. [PubMed: 12577059]

14. Rossetti S, Burton S, Strmecki L, et al. The position of the polycystic kidney disease 1 (PKD1) gene mutation correlates with the severity of renal disease. J. Am. Soc. Nephrol 2002;13:1230-37. [PubMed: 11961010]

15. Magistroni R, He N, Wang K, et al. Genotype-renal function correlation in type 2 autosomal dominant polycystic kidney disease. J. Am. Soc. Nephrol 2003;14:1164-74. [PubMed: 12707387]

16. Rossetti S, Chauveau D, Kubly V, et al. Association of mutation position in polycystic kidney disease 1 (PKD1) gene and development of a vascular phenotype. Lancet 2003;361:2196-201. [PubMed: 12842373]

17. Connor A, Lunt PW, Dolling C, et al. Mosaicism in autosomal dominant polycystic kidney disease revealed by genetic testing to enable living related renal transplantation. Am. J. Transplant 2008;8:232-37. [PubMed: 17973957]

18. Consugar MB, Wong WC, Lundquist PA, et al. Characterization of large rearrangements in autosomal dominant polycystic kidney disease and the PKD1/TSC2 contiguous gene syndrome. Kidney Int. 2008 online doi:10-1078/Ki.2008.485.

19. Lu W, Peissel B, Babakhanlou H, et al. Perinatal lethality with kidney and pancreas defects in mice with a targeted $P k d 1$ mutation. Nature Genet 1997;17:179-81. [PubMed: 9326937]

20. Lu W, Fan X, Basora N, et al. Late onset of renal and hepatic cysts in Pkdl-targeted heterozygotes. Nature Genet 1999;21:160-61. [PubMed: 9988265]

21. Lantinga-van Leeuwen IS, Leonhard WN, Van Der Wal A, et al. Kidney-specific inactivation of the Pkd1 gene induces rapid cyst formation in developing kidneys and a slow onset of disease in adult mice. Hum. Mol. Genet 2007;16:3188-96. [PubMed: 17932118]

22. Piontek K, Menezes LF, Garcia-Gonzalez MA, et al. A critical developmental switch defines the kinetics of kidney cyst formation after loss of Pkd1. Nat. Med 2007;13:1490-95. [PubMed: 17965720] 
23. Pei Y, Watnick T, He N, et al. Somatic $P K D 2$ mutations in individual kidney and liver cysts support a "two-hit" model of cystogenesis in type 2 autosomal dominant polycystic kidney disease. J. Am. Soc. Nephrol 1999;10:1524-29. [PubMed: 10405208]

24. Qian F, Watnick TJ, Onuchic LF, et al. The molecular basis of focal cyst formation in human autosomal dominant polycystic kidney disease type 1. Cell 1996;87:979-87. [PubMed: 8978603]

25. Wu G, D'Agati V, Cai Y, et al. Somatic inactivation of $P k d 2$ results in polycystic kidney disease. Cell 1998;93:177-88. [PubMed: 9568711]

26. Lantinga-van Leeuwen IS, Dauwerse JG, Baelde HJ, et al. Lowering of Pkd1 expression is sufficient to cause polycystic kidney disease. Hum. Mol. Genet 2004;13:3069-77. [PubMed: 15496422]

27. Ponting CP, Hofmann K, Bork P. A latrophilin/CL-1-like GPS domain in polycystin-1. Curr. Biol 1999;9:R585-88. [PubMed: 10469603]

28. Sandford R, Sgotto B, Aparacio S, et al. Comparative analysis of the polycystic kidney disease 1 (PKD1) gene reveals an integral membrane glycoprotein with multiple evolutionary conserved domains. Hum. Mol. Genet 1997;6:1483-89. [PubMed: 9285785]

29. Gonzalez-Perrett S, Kim K, Ibarra C, et al. Polycystin-2, the protein mutated in autosomal dominant polycystic kidney disease (ADPKD), is a $\mathrm{Ca}^{2+}$-permeable nonselective cation channel. Proc. Natl. Acad. Sci. USA 2001;98:1182-87. [PubMed: 11252306]

30. Koulen P, Cai Y, Geng L, et al. Polycystin-2 is an intracellular calcium release channel. Nat. Cell Biol 2002;4:191-97. [PubMed: 11854751]

31. Qian F, Boletta A, Bhunia AK, et al. Cleavage of polycystin-1 requires the receptor for egg jelly domain and is disrupted by human autosomal-dominant polycystic kidney disease 1-associated mutations. Proc. Natl. Acad. Sci. USA 2002;99:16981-86. [PubMed: 12482949]

32. Yu S, Hackmann K, Gao J, et al. Essential role of cleavage of polycystin-1 at G protein-coupled receptor proteolytic site for kidney tubular structure. Proc. Natl. Acad. Sci. USA 2007;104:1868893. [PubMed: 18003909]

33. Chauvet V, Tian X, Husson $\mathrm{H}$, et al. Mechanical stimuli induce cleavage and nuclear translocation of the polycystin-1 C terminus. J. Clin. Invest 2004;114:1433-43. [PubMed: 15545994]

34. Low SH, Vasanth S, Larson CH, et al. Polycystin-1, STAT6, and P100 function in a pathway that transduces ciliary mechanosensation and is activated in polycystic kidney disease. Dev. Cell 2006;10:57-69. [PubMed: 16399078]

35. Li X, Luo Y, Starremans PG, et al. Polycystin-1 and polycystin-2 regulate the cell cycle through the helix-loop-helix inhibitor Id2. Nat. Cell Biol 2005;7:1102-12.

36. Pazour GJ, San Agustin JT, Follit JA, et al. Polycystin-2 localizes to kidney cilia and the ciliary level is elevated in orpk mice with polycystic kidney disease. Curr. Biol 2002;12:R378-80. [PubMed: 12062067]

37. Yoder BK, Hou X, Guay-Woodford LM. The polycystic kidney disease proteins, polycystin-1, polycystin-2, polaris, and cystin, are colocalized in renal cilia. J. Am. Soc. Nephrol 2002;13:250816. [PubMed: 12239239]

38. Lin F, Hiesberger T, Cordes K, et al. Kidney-specific inactivation of the KIF3A subunit of kinesinII inhibits renal ciliogenesis and produces polycystic kidney disease. Proc. Natl. Acad. Sci. USA 2003;100:5286-91. [PubMed: 12672950]

39. Nauli SM, Alenghat FJ, Luo Y, et al. Polycystins 1 and 2 mediate mechanosensation in the primary cilium of kidney cells. Nat. Genet 2003;33:129-37. [PubMed: 12514735]

40. Praetorius HA, Spring KR. Bending the MDCK cell primary cilium increases intracellular calcium. J. Membr. Biol 2001;184:71-79. [PubMed: 11687880]

41. Pisitkun T, Shen RF, Knepper MA. Identification and proteomic profiling of exosomes in human urine. Proc. Natl. Acad. Sci. USA 2004;101:13368-73. [PubMed: 15326289]

42. Hogan MC, Manganelli L, Woollard JR, et al. Characterization of polycystic kidney disease protein (PKD) positive exosome-like vesicles. J. Am. Soc. Nephrol. 2008 In press.

43. Tanaka Y, Okada Y, Hirokawa N. FGF-induced vesicular release of Sonic hedgehog and retinoic acid in leftward nodal flow is critical for left-right determination. Nature 2005;435:172-77. [PubMed: 15889083]

44. McGrath J, Somlo S, Makova S, et al. Two populations of node monocilia initiate left-right asymmetry in the mouse. Cell 2003;114:61-73. [PubMed: 12859898] 
45. Pennekamp P, Karcher C, Fischer A, et al. The ion channel polycystin-2 is required for left-right axis determination in mice. Curr. Biol 2002;12:938-43. [PubMed: 12062060]

46. Ong AC, Harris PC. Molecular pathogenesis of ADPKD: the polycystin complex gets complex. Kidney Int 2005;67:1234-47. [PubMed: 15780076]

47. Sutton KA, Jungnickel MK, Florman HM. A polycystin-1 controls postcopulatory reproductive selection in mice. Proc. Natl. Acad. Sci. USA 2008;105:8661-66. [PubMed: 18562295]

48. Ishimaru Y, Inada H, Kubota M, et al. Transient receptor potential family members PKD1L3 and PKD2L1 form a candidate sour taste receptor. Proc. Natl. Acad. Sci. USA 2006;103:12569-74. [PubMed: 16891422]

49. Huang AL, Chen X, Hoon MA, et al. The cells and logic for mammalian sour taste detection. Nature 2006;442:934-38. [PubMed: 16929298]

50. Yamaguchi T, Hempson SJ, Reif GA, et al. Calcium restores a normal proliferation phenotype in human polycystic kidney disease epithelial cells. J. Am. Soc. Nephrol 2006;17:178-87. [PubMed: 16319189]

51. Gattone VH 2nd, Wang X, Harris PC, et al. Inhibition of renal cystic disease development and progression by a vasopressin V2 receptor antagonist. Nat. Med 2003;9:1323-26. [PubMed: 14502283]

52. Torres VE, Wang X, Qian Q, et al. Effective treatment of an orthologous model of autosomal dominant polycystic kidney disease. Nature Med 2004;10:363-64. [PubMed: 14991049]

53. Yamaguchi T, Nagao S, Kasahara M, et al. Renal accumulation and excretion of cyclic adenosine monophosphate in a murine model of slowly progressive polycystic kidney disease. Am. J. Kidney Dis 1997;30:703-9. [PubMed: 9370187]

54. Yamaguchi T, Nagao S, Wallace DP, et al. Cyclic AMP activates B-Raf and ERK in cyst epithelial cells from autosomal-dominant polycystic kidneys. Kidney Int 2003;63:1983-94. [PubMed: 12753285]

55. Yamaguchi T, Pelling JC, Ramaswamy NT, et al. cAMP stimulates the in vitro proliferation of renal cyst epithelial cells by activating the extracellular signal-regulated kinase pathway. Kidney Int 2000;57:1460-71. [PubMed: 10760082]

56. Yamaguchi T, Wallace DP, Magenheimer BS, et al. Calcium restriction allows cAMP activation of the B-Raf/ERK pathway, switching cells to a cAMP-dependent growth-stimulated phenotype. J. Biol. Chem 2004;279:40419-30. [PubMed: 15263001]

57. Sampson JR, Maheshwar MM, Aspinwall R, et al. Renal cystic disease in tuberous sclerosis: role of the polycystic kidney disease 1 gene. Am. J. Hum. Genet 1997;61:843-51. [PubMed: 9382094]

58. Shillingford JM, Murcia NS, Larson CH, et al. The mTOR pathway is regulated by polycystin-1, and its inhibition reverses renal cystogenesis in polycystic kidney disease. Proc. Natl. Acad. Sci. USA 2006;103:5466-71. [PubMed: 16567633]

59. Masyuk TV, Masyuk AI, Torres VE, et al. Octreotide inhibits hepatic cystogenesis in a rodent model of polycystic liver disease by reducing cholangiocyte adenosine $3^{\prime}, 5^{\prime}$-cyclic monophosphate. Gastroenterology 2007;132:1104-16. [PubMed: 17383431]

60. Ruggenenti P, Remuzzi A, Ondei P, et al. Safety and efficacy of long-acting somatostatin treatment in autosomal-dominant polycystic kidney disease. Kidney Int 2005;68:206-16. [PubMed: 15954910]

61. Qian Q, Du H, King BF, et al. Sirolimus reduces polycystic liver volume in ADPKD patients. J. Am. Soc. Nephrol 2008;19:631-38. [PubMed: 18199797]

62. Yang B, Sonawane ND, Zhao D, et al. Small-molecule CFTR inhibitors slow cyst growth in polycystic kidney disease. J. Am. Soc. Nephrol 2008;19:1300-10. [PubMed: 18385427]

63. Albaqumi M, Srivastava S, Li Z, et al. KCa3.1 potassium channels are critical for cAMP-dependent chloride secretion and cyst growth in autosomal-dominant polycystic kidney disease. Kidney Int 2008;74:740-49. [PubMed: 18547995]

64. Alper SL. Let's look at cysts from both sides now. Kidney Int 2008;74:699-702. [PubMed: 18756294]

65. Leuenroth SJ, Okuhara D, Shotwell JD, et al. Triptolide is a traditional Chinese medicine-derived inhibitor of polycystic kidney disease. Proc. Natl. Acad. Sci. USA 2007;104:4389-94. [PubMed: 17360534]

66. Leuenroth SJ, Bencivenga N, Igarashi P, et al. Triptolide reduces cystogenesis in a model of ADPKD. J. Am. Soc. Nephrol 2008;19:1659-62. [PubMed: 18650476] 
67. Sweeney WE Jr, von Vigier RO, Frost P, et al. Src inhibition ameliorates polycystic kidney disease. J. Am. Soc. Nephrol 2008;19:1331-41. [PubMed: 18385429]

68. Wilson SJ, Amsler K, Hyink DP, et al. Inhibition of HER-2(neu/ErbB2) restores normal function and structure to polycystic kidney disease (PKD) epithelia. Biochim. Biophys. Acta 2006;1762:647-55. [PubMed: 16797938]

69. Sweeney WE Jr, Hamahira K, Sweeney J, et al. Combination treatment of PKD utilizing dual inhibition of EGF-receptor activity and ligand bioavailability. Kidney Int 2003;64:1310-19. [PubMed: 12969149]

70. Tao Y, Kim J, Yin Y, et al. VEGF receptor inhibition slows the progression of polycystic kidney disease. Kidney Int 2007;72:1358-66. [PubMed: 17882148]

71. Li X, Magenheimer BS, Xia S, et al. A tumor necrosis factor-alpha-mediated pathway promoting autosomal dominant polycystic kidney disease. Nat. Med 2008;14:863-68. [PubMed: 18552856]

72. Park F, Sweeney WE, Jia G, et al. 20-HETE mediates proliferation of renal epithelial cells in polycystic kidney disease. J. Am. Soc. Nephrol 2008;19(10):1929-39. [PubMed: 18596124]

73. Higashihara E, Nutahara K, Horie S, et al. The effect of eicosapentaenoic acid on renal function and volume in patients with ADPKD. Nephrol. Dial. Transplant 2002;23:2847-52. [PubMed: 18372389]

74. Bukanov NO, Smith LA, Klinger KW, et al. Long-lasting arrest of murine polycystic kidney disease with CDK inhibitor roscovitine. Nature 2006;444:949-52. [PubMed: 17122773]

75. Guay-Woodford LM, Desmond RA. Autosomal recessive polycystic kidney disease: the clinical experience in North America. Pediatrics 2003;111:1072-80. [PubMed: 12728091]

76. Adeva M, El-Youssef M, Rossetti S, et al. Clinical and molecular characterization defines a broadened spectrum of autosomal recessive polycystic kidney disease (ADPKD). Medicine 2006;85:1-21. [PubMed: 16523049]

77. Onuchic LF, Furu L, Nagasawa Y, et al. PKHD1, the polycystic kidney and hepatic disease 1 gene, encodes a novel large protein containing multiple immunoglobulin-like plexin-transcription-factor domains and parallel beta-helix 1 repeats. Am. J. Hum. Genet 2002;70:1305-17. [PubMed: 11898128]

78. Ward CJ, Hogan MC, Rossetti S, et al. The gene mutated in autosomal recessive polycystic kidney disease encodes a large, receptor-like protein. Nat. Genet 2002;30:259-69. [PubMed: 11919560]

79. Bergmann C, Senderek J, Sedlacek B, et al. Spectrum of mutations in the gene for autosomal recessive polycystic kidney disease (ARPKD/PKHD1). J. Am. Soc. Nephrol 2003;14:76-89. [PubMed: 12506140]

80. Moser M, Matthiesen S, Kirfel J, et al. A mouse model for cystic biliary dysgenesis in autosomal recessive polycystic kidney disease (ARPKD). Hepatology 2005;41:1113-21. [PubMed: 15830394]

81. Woollard JR, Punyashtiti R, Richardson S, et al. A mouse model of autosomal recessive polycystic kidney disease with biliary duct and proximal tubule dilatation. Kidney Int 2007;72:328-36. [PubMed: 17519956]

82. Mai W, Chen D, Ding T, et al. Inhibition of Pkhdl impairs tubulomorphogenesis of cultured IMCD cells. Mol. Biol. Cell 2005;16:4398-409. [PubMed: 15975909]

83. Masyuk TV, Huang BQ, Ward CJ, et al. Defects in cholangiocyte fibrocystin expression and ciliary structure in the PCK rat. Gastroenterology 2003;125:1303-10. [PubMed: 14598246]

84. Kim I, Fu Y, Hui K, et al. Fibrocystin/polyductin modulates renal tubular formation by regulating polycystin-2 expression and function. J. Am. Soc. Nephrol 2008;19:455-68. [PubMed: 18235088]

85. Wang S, Zhang J, Nauli SM, et al. Fibrocystin/polyductin, found in the same protein complex with polycystin-2, regulates calcium responses in kidney epithelia. Mol. Cell Biol 2007;27:3241-52. [PubMed: 17283055]

86. Ward CJ, Yuan D, Masyuk TV, et al. Cellular and subcellular localization of the ARPKD protein; fibrocystin is expressed on primary cilia. Hum. Mol. Genet 2003;12:2703-10. [PubMed: 12925574]

87. Wu Y, Dai XQ, Li Q, et al. Kinesin-2 mediates physical and functional interactions between polycystin-2 and fibrocystin. Hum. Mol. Genet 2006;15:3280-92. [PubMed: 17008358]

88. Kaimori JY, Nagasawa Y, Menezes LF, et al. Polyductin undergoes notch-like processing and regulated release from primary cilia. Hum. Mol. Genet 2007;16:942-56. [PubMed: 17470460] 
89. Hiesberger T, Gourley E, Erickson A, et al. Proteolytic cleavage and nuclear translocation of fibrocystin is regulated by intracellular $\mathrm{Ca}^{2+}$ and activation of protein kinase C. J. Biol. Chem 2006;281:34357-64. [PubMed: 16956880]

90. Hogan MC, Griffin MD, Rossetti S, et al. PKHDL1, a homolog of the autosomal recessive polycystic kidney disease gene, encodes a receptor with inducible T lymphocyte expression. Hum. Mol. Genet 2003;12:685-89. [PubMed: 12620974]

91. Fliegauf M, Benzing T, Omran H. When cilia go bad: cilia defects and ciliopathies. Nat. Rev. Mol. Cell Biol 2007;8:880-93. [PubMed: 17955020]

92. Hildebrandt F, Zhou W. Nephronophthisis-associated ciliopathies. J. Am. Soc. Nephrol 2007;18:1855-71. [PubMed: 17513324]

93. Harris PC. Genetic complexity in Joubert syndrome and related disorders. Kidney Int 2007;72:142123. [PubMed: 18046420]

94. Beales PL. Lifting the lid on Pandora's box: the Bardet-Biedl syndrome. Curr. Opin. Genet. Dev 2005;15:315-23. [PubMed: 15917208]

95. Ferrante MI, Giorgio G, Feather SA, et al. Identification of the gene for oral-facial-digital type I syndrome. Am. J. Hum. Genet 2001;68:569-76. [PubMed: 11179005]

96. Badano JL, Kim JC, Hoskins BE, et al. Heterozygous mutations in BBS1, BBS2 and BBS6 have a potential epistatic effect on Bardet-Biedl patients with two mutations at a second BBS locus. Hum. Mol. Genet 2003;12:1651-59. [PubMed: 12837689]

97. Hoefele J, Wolf MT, O'Toole JF, et al. Evidence of oligogenic inheritance in nephronophthisis. J. Am. Soc. Nephrol 2007;18:2789-95. [PubMed: 17855640]

98. Leitch CC, Zaghloul NA, Davis EE, et al. Hypomorphic mutations in syndromic encephalocele genes are associated with Bardet-Biedl syndrome. Nat. Genet 2008;40:443-48. [PubMed: 18327255]

99. Arts HH, Doherty D, van Beersum SE, et al. Mutations in the gene encoding the basal body protein RPGRIP1L, a nephrocystin-4 interactor, cause Joubert syndrome. Nat. Genet 2007;39:882-88. [PubMed: 17558407]

100. Huangfu D, Liu A, Rakeman AS, et al. Hedgehog signalling in the mouse requires intraflagellar transport proteins. Nature 2003;426:83-87. [PubMed: 14603322]

101. Haycraft CJ, Banizs B, Aydin-Son Y, et al. Gli2 and Gli3 localize to cilia and require the intraflagellar transport protein polaris for processing and function. PLoS Genet 2005;1:e53. [PubMed: 16254602]

102. Attanasio M, Uhlenhaut NH, Sousa VH, et al. Loss of GLIS2 causes nephronophthisis in humans and mice by increased apoptosis and fibrosis. Nat. Genet 2007;39:1018-24. [PubMed: 17618285]

103. Ross AJ, May-Simera H, Eichers ER, et al. Disruption of Bardet-Biedl syndrome ciliary proteins perturbs planar cell polarity in vertebrates. Nat. Genet 2005;37:1135-40. [PubMed: 16170314]

104. Simons M, Gloy J, Ganner A, et al. Inversin, the gene product mutated in nephronophthisis type II, functions as a molecular switch between Wnt signaling pathways. Nat. Genet 2005;37:537-43. [PubMed: 15852005]

105. Fischer E, Legue E, Doyen A, et al. Defective planar cell polarity in polycystic kidney disease. Nat. Genet 2006;38:21-23. [PubMed: 16341222]

\section{RELATED RESOURCES}

The PKD Foundation: http://www.pkdcure.org/

The ARPKD Mutation Database:

http://www.humgen.rwth-aachen.de/index.asp?subform=database.html\&nav=database_nav.html

The ADPKD Mutation Database: http://pkdb.mayo.edu/ 


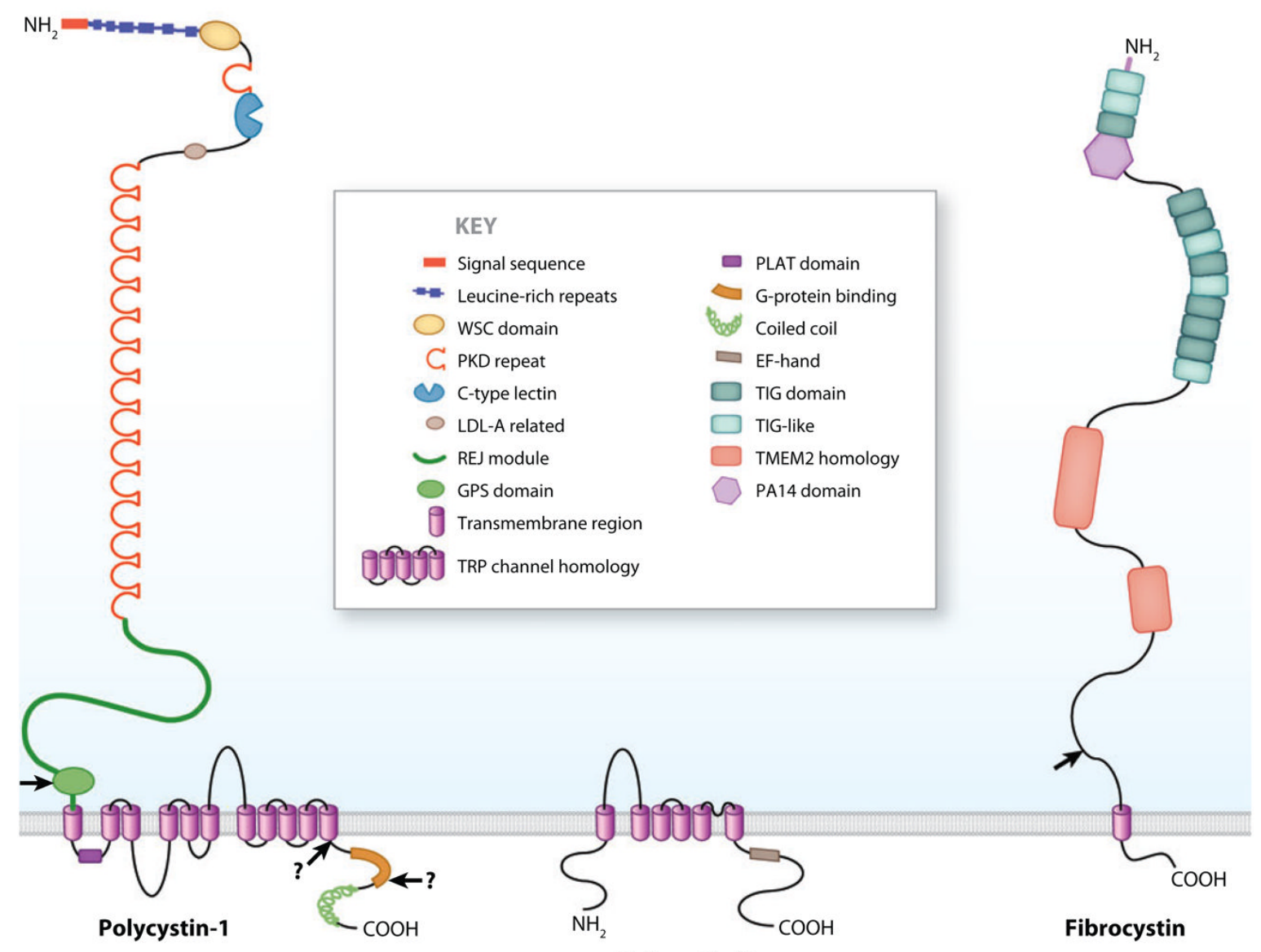

Polycystin-2

Figure 1.

Structures of the ADPKD proteins polycystin-1 and -2 and the ARPKD protein, fibrocystin. Details of domains found in these proteins are shown in the key. Arrows indicate places where the proteins are thought to be cleaved. 


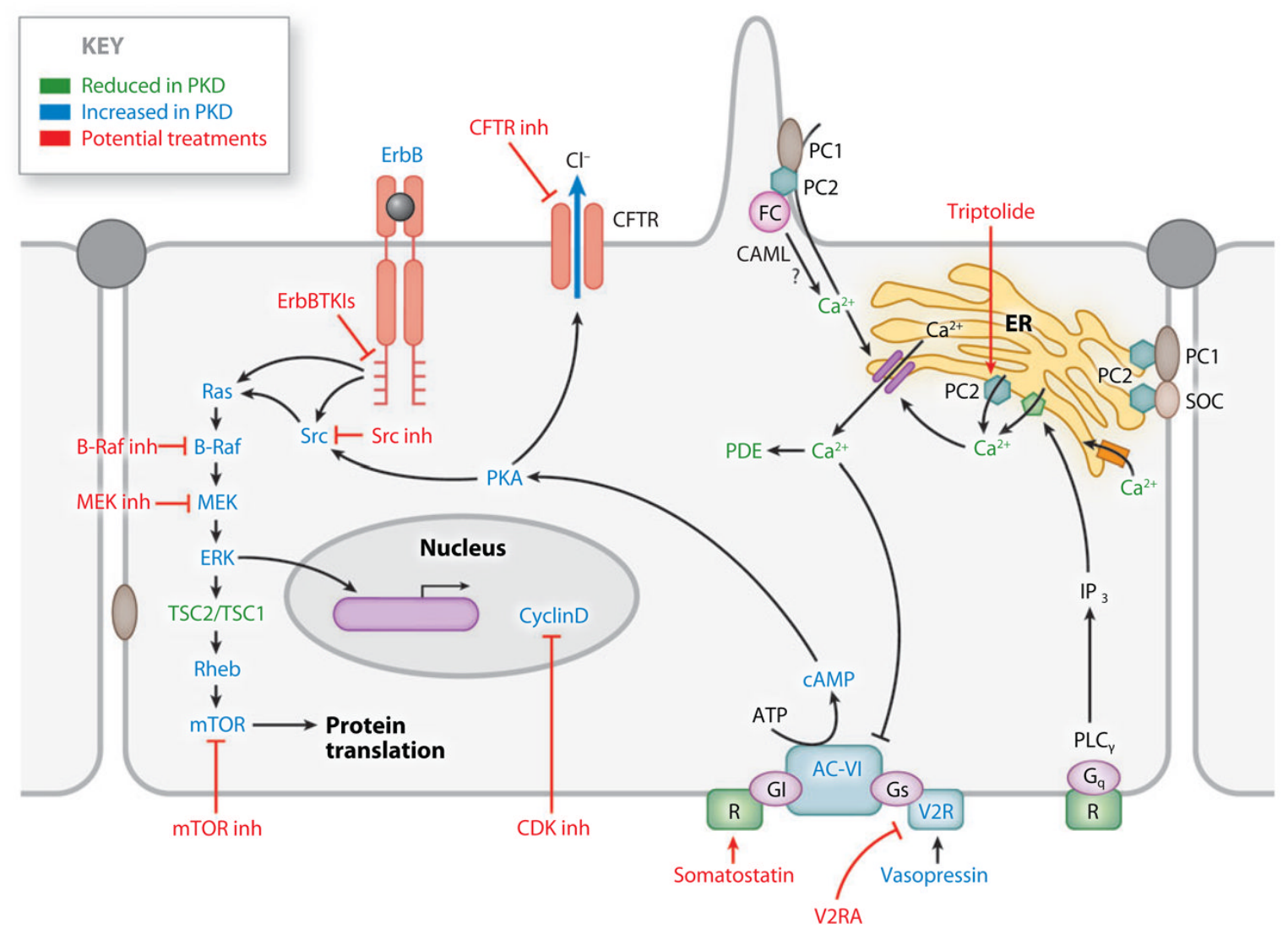

Figure 2.

Cellular changes associated with polycystic kidney disease (PKD). Components and pathways that are downregulated and upregulated in PKD are indicated. Potential treatments that target these defective pathways are shown in red. 


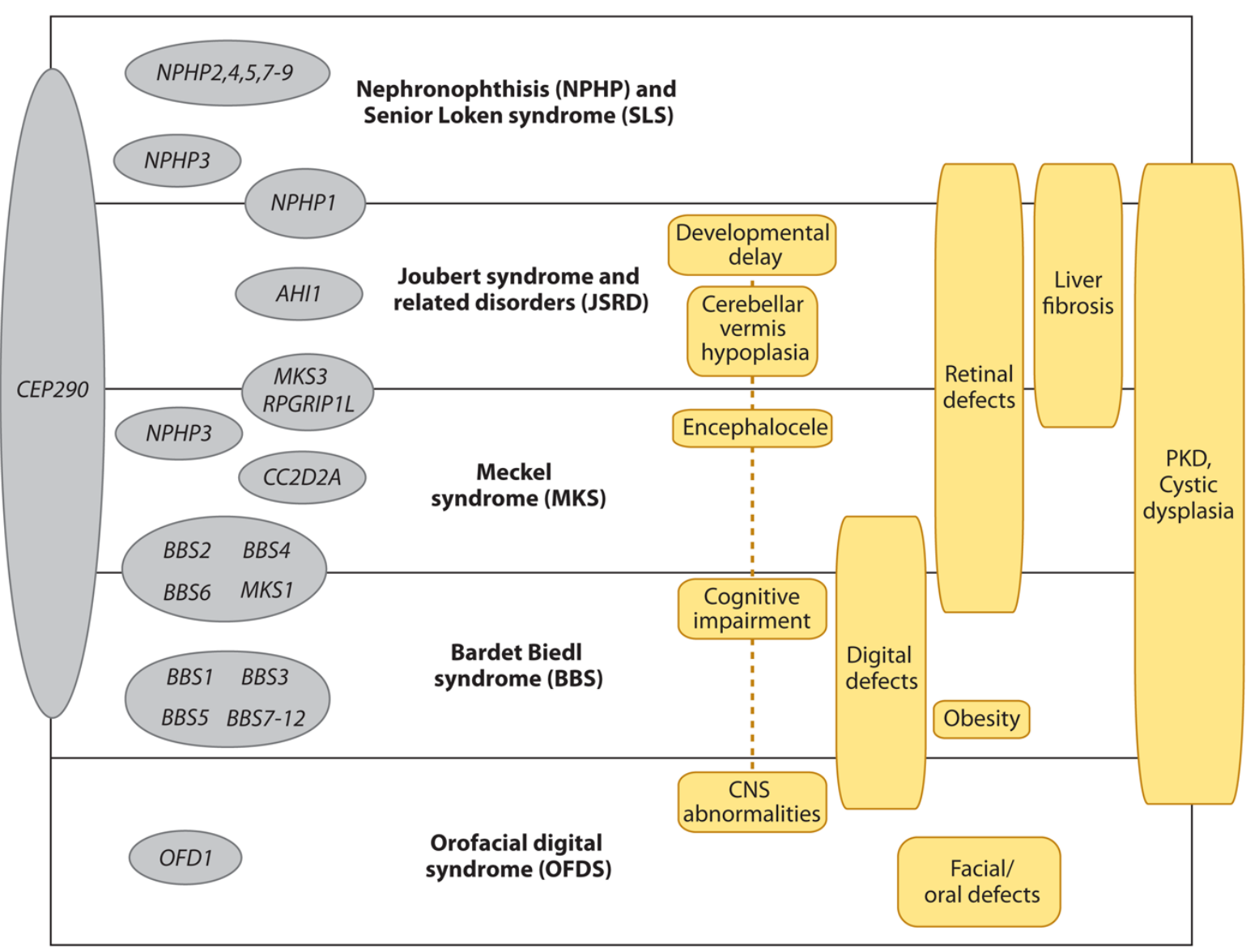

Figure 3.

Genes and phenotypic abnormalities associated with syndromic forms of PKD. Diseases are listed in the center; genes associated with them are shown on the left (gray). On the right are phenotypes found in these different disorders (yellow). Note the high degree of overlap in genes and phenotypes between the different disorders. 


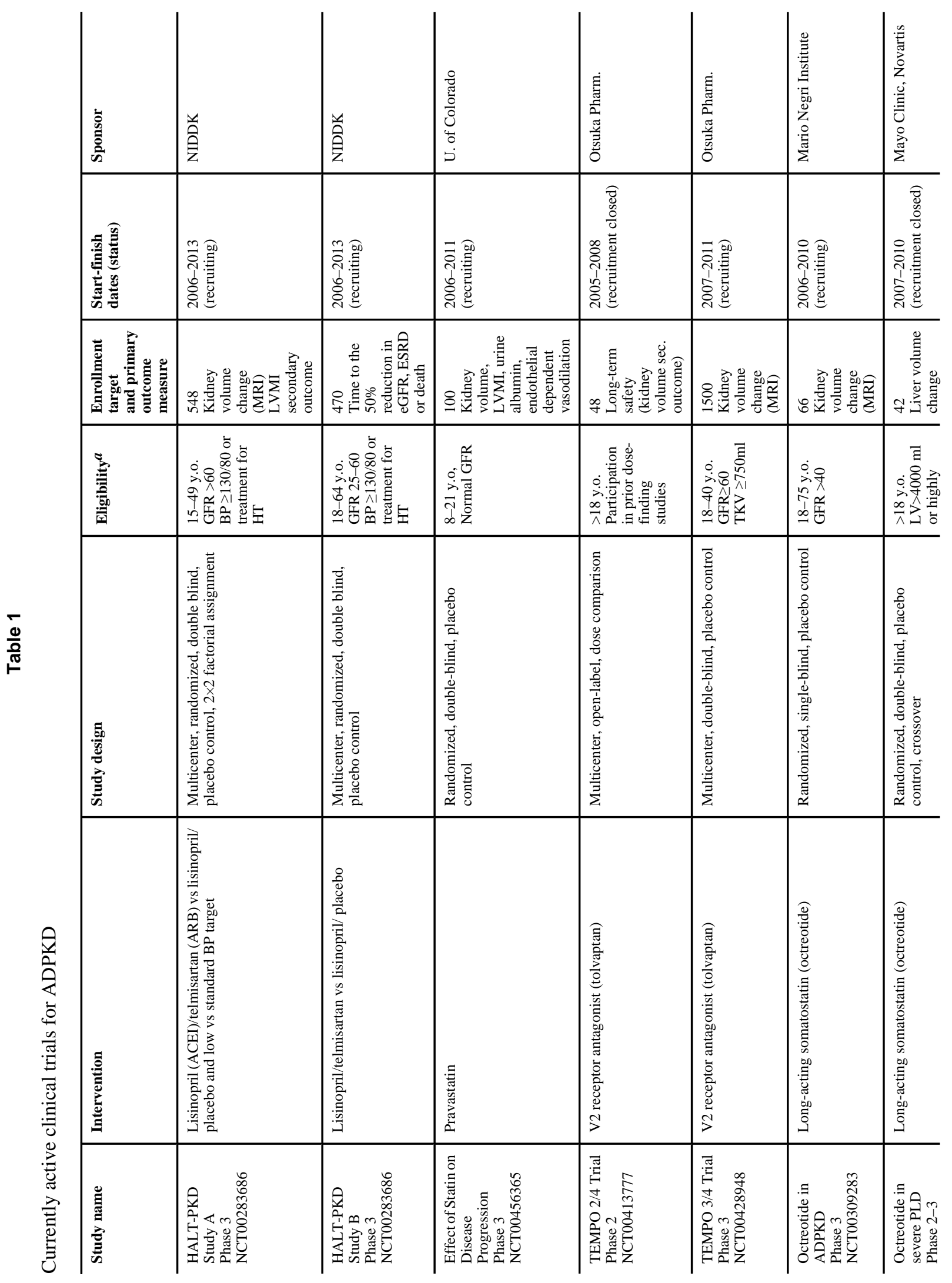




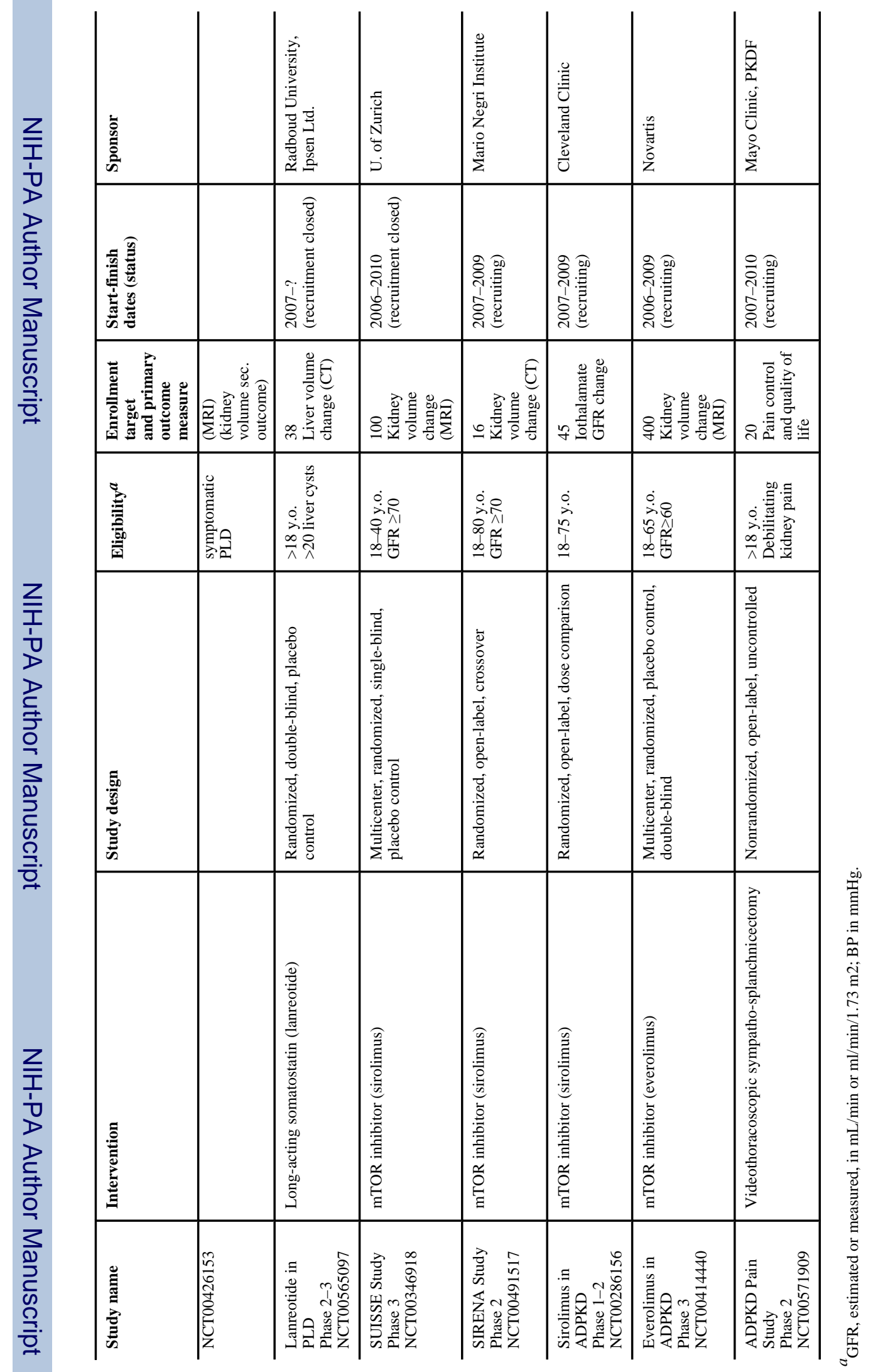

